\section{"Hasta no ver no creer"; desconfianza mexicana en los albores de la pandemia}

\author{
RICARDO DUARTE-BAJAÑA ${ }^{1}$
}

0000-0001-5436-7439

Universidad Autónoma del Estado de México, México.

\section{Resumen}

A través del trabajo etnográfico que 21 estudiantes de la asignatura Investigación Cualitativa realizaron en sus hogares durante la cuarentena ocasionada por la Covid19, este artículo revela como la población analizada presenta distintos relatos de desconfianza dirigidos tanto hacia la propia existencia del virus, como a la efectividad de la vacuna contra el mismo. Estos relatos de desconfianza están basados en teorías conspirativas, en la manipulación mediática que algunos entrevistados aducen y en la estrategia del propio gobierno tanto para controlar la extensión de la pandemia como para concienciar a los ciudadanos, a través de su propio ejemplo, de tomar medidas sanitarias y de distanciamiento social.

Palabras clave: Covid-19; México; Etnografía; Desconfianza; Conspiraciones; Pandemia.

Abstract "Has to be seen to be believed"; Mexican distrust at the dawn of the pandemic

Through the ethnographic work that 21 students of the Qualitative Research course carried out in their homes during the quarantine caused by Covid-19, this article reveals how the analysed population presents different stories of mistrust directed

\footnotetext{
${ }^{1}$ Contacto: Ricardo Duarte Bajaña - ridubaco@gmail.com
}

revistes.uab.cat/periferia

Junio 2021 albores de la pandemia. Perifèria, revista de recerca i formació en antropologia, https://doi.org/10.5565/rev/periferia.838
Duarte-Bajaña, R. (2021). "Hasta no ver 
both towards the very existence of the virus, and towards the effectiveness of the vaccine against it. These stories of mistrust are based on conspiracy theories, on the media manipulation that some interviewees adduce and, on the government's, own strategy both to control the spread of the pandemic and to make citizens aware, through their own example, of taking measures. health and social distancing.

Keywords: Covid-19; México; Ethnography; Distrust; Conspiracies; Pandemic.

\section{Introducción}

Desde el mes de febrero del año 2020 el virus SARS-CoV-2, que genera la enfermedad COVID-19, arribó a México. Desde el 23 de marzo se propuso la Jornada Nacional de Sana Distancia para evitar los contagios. Se trata de una serie de recomendaciones que, entre otras medidas, incluyen el uso de tapabocas, cuarentena e interacción social con distancia. Una parte de la población ha acatado estas recomendaciones. Sin embargo, teniendo en cuenta que el $57 \%$ del trabajo en México es informal y que el $50 \%$ de la población tiene ingresos por debajo de la línea de bienestar (Ramírez López, 2019), mucha gente no ha podido quedarse en cuarentena.

El objetivo de este texto consiste en explorar algunos aspectos de la vida social durante la pandemia del coronavirus, haciendo énfasis en la desconfianza como una de las características centrales de las relaciones sociales en este contexto de riesgo sanitario. Vale la pena enfatizar que se trata de un avance inicial de una investigación en curso. En esta investigación se destaca la reticencia de algunos ciudadanos a seguir indicaciones como usar tapabocas o mantener la distancia social. Estos comportamientos fueron recurrentes a lo largo del trabajo de campo realizado durante la investigación que sostiene este artículo.

\section{Marco contextual y metodología}

La desconfianza social frente a las recomendaciones sanitarias en México durante crisis sociales y de salud es un tema que ha sido abordado por las Ciencias Sociales (Fernández Poncela, 2012). Por ejemplo, durante el reciente brote de zika, virus con una letalidad mucho menor que el SARS-CoV-2, se reportó que la desconfianza social 
frente al virus y a las recomendaciones estatales tenía orígenes en la ineficiencia sanitaria sobre el brote, en la falta de información y en los vínculos de los medios de comunicación con intereses políticos (Rodríguez Medina, Pandal de la Peza y Shrum, 2019). La pandemia de COVID-19 se inició durante el primer semestre de 2020, a partir de la recomendación gubernamental de cuarentena, las instituciones de educación superior cerraron sus puertas y las clases se empezaron a hacer de manera virtual. Teniendo en cuenta esta coyuntura, se propuso replantear la metodología de la asignatura Investigación Cualitativa, de la Licenciatura en Cultura Física de la Universidad Autónoma del Estado de México. Entre otros procesos didácticos, desde el 23 de marzo hasta el 26 de abril del año 2020, 21 estudiantes tuvieron experiencias etnográficas dentro de sus propios hogares con el objetivo de recabar datos que permitieran comprender las dinámicas de la vida social de las familias durante la pandemia. Cada estudiante escribió diarios de campo a partir de la observación participante y fueron revisados y comentados semanalmente por el docente responsable.

Además de la observación participante, durante la cuarta semana de recolección de información, cada estudiante realizó una entrevista semiestructurada a un integrante de su familia. Posteriormente se realizó una codificación abierta inicial (Strauss y Corbin, 2002) de los diarios de campo y de la entrevista semiestructurada. En este artículo se hará referencia a uno de los ejes de análisis que buscó identificar percepciones frente al COVID-19.

Los estudiantes mencionados asistían a clase en una sede de la universidad ubicada en la ciudad de Toluca, capital del Estado de México, situada a 66 kilómetros de la Ciudad de México. Este Estado es el más densamente poblado de la República Mexicana, con aproximadamente 20 millones de habitantes. De los 21 estudiantes que participaron en esta experiencia etnográfica, 5 residían en la ciudad de Toluca; uno vivía en Morelia, Michoacán y los demás vivían en diferentes municipios dentro del Estado de México. Antes de la pandemia, durante el periodo escolar, muchos estudiantes que vivían fuera de Toluca rentaban lugares para vivir en esta ciudad y viajaban a ver a sus familias los fines de semana o en época de vacaciones. Durante la cuarentena por COVID-19 todos regresaron a sus hogares para permanecer con sus familias. 
Si bien, algunos de los municipios en donde residían las familias de estos estudiantes han experimentado procesos de modernización e incluso de gentrificación (Gómez Carmona, Villar Calvo e Inzulza Contardo, 2016; Jiménez Sánchez y Calderón Maya, 2016), gran parte de sus relaciones sociales giran en torno a formas sociales mesoamericanas como sistemas de cargos (Chance y Taylor, 1985; Mulhare, 2000; Magazine, 2015), familia extensa mesoamericana (Robichaux, 2002) y religiosidad vinculada con diferentes procesos culturales (Mulhare, 2000).

\section{Las variaciones de la desconfianza}

En las familias observadas existían diversas percepciones frente al COVID-19. Algunas personas consideraban que era necesario tomar todas las medidas de precaución para no ser contagiados. Mientras tanto, otros sujetos asumían que se trataba de una invención. Por ejemplo, uno de los participantes resaltó lo siguiente: "En nuestra casa todos tienen distintos puntos de vista sobre el Covid-19; mi papá dice que no existe, que es "puro cuento", todos los demás si creemos en su existencia, pero con algunas dudas" (José Coyote, diario de campo, marzo 31, 2020).

Desde aquellos primeros meses de pandemia la sensación de algunas personas que sí creían en la existencia del virus era de temor e incertidumbre por posibles contagios. Era común que los integrantes de las familias manifestaran su molestia e impotencia frente a aquellas personas que no creían en el SARS-CoV-2. La mamá de uno de los participantes señaló al respecto:

Se siente un poco de coraje, de impotencia, pues algunos estamos tratando de llevar las cosas bien, con las recomendaciones que se nos dan, pero algunas otras personas no ponen de su parte, entran a las tiendas hasta con niños y andan ahí como si nada pasara, yo considero que no es correcto porque pues esto podría agravarse. (Josué Rodríguez, entrevista a su mamá, minuto 14:34, marzo 26, 2020).

En este mismo sentido, uno de los estudiantes reportó lo siguiente:

En la televisión salió un corte informativo que decía que en el mercado de La Merced en la Ciudad de México las personas no acatan las medidas de seguridad y que es un foco de infección considerable, mi mamá vio eso y se puso a llorar 
y al parecer le dio mucho coraje y tristeza, dijo: "¿qué somos tan pendejos los mexicanos como para no darnos cuenta de lo que está pasando?". (Tzolkin Zapi, diario de campo, abril 23, 2020).

Se trata de una diversidad de criterios frente a la pandemia que, paulatinamente, van generando nuevos rumores, incertidumbre y desconfianza. Uno de estos rumores que circulaba con fuerza era la idea de que ciertos hospitales públicos estaban recibiendo partidas presupuestales adicionales para soportar los trámites relacionados con las personas que fallecían por COVID-19. Una joven señaló que uno de sus familiares, quien trabaja como directivo en un reconocido hospital de Toluca, le contó que existen prácticas reprochables en aquella institución: "... a las personas que fallecieron por otras enfermedades o también por COVID se les tenía que poner en el acta de defunción que la causa de muerte era COVID-19" (Tzolkin Zapi, diario de campo, abril 23, 2020).

En este problemático contexto, uno de los estudiantes reportó lo siguiente: "Mi papá dice que [el COVID] es un invento del gobierno, que hasta que no vea personalmente a alguien muerto de coronavirus no va a creer" (José Gabriel Coyote, diario de campo, marzo 30, 2020). Al ser interrogado respecto a su percepción frente a la pandemia, el familiar de uno de los estudiantes respondió "hasta no ver no creer", (Daniel Mejía, diario de campo, mayo 3, 2020). De igual forma, algunas personas entrevistadas manifestaban que seguirían las recomendaciones de seguridad frente al COVID-19 solamente cuando alguien de su familia o de su comunidad resultara contagiado; mientras tanto, continuarían asumiendo que el virus no existía.

Mientras transcurrían las semanas en medio de la pandemia, un problema empezó a hacerse cada vez más fuerte en México impactando también a algunas familias y estudiantes que participaron en esta experiencia. Si bien algunas familias tenían la posibilidad de permanecer en cuarentena, un gran número de personas debían salir a trabajar porque sus actividades laborales se ubicaban en la informalidad o porque sus familiares se quedaron sin empleo. Este fue el caso de uno de los alumnos, que se vio obligado a realizar diversas labores como lavar carros y vender barbacoa en Ciudad de México. Sus experiencias nos permitieron acercarnos un poco más a la incertidumbre que algunas personas vivían frente a la pandemia. En uno de sus textos escribió lo siguiente: 
No es difícil lavar camionetas, pero es laborioso, deben quedar muy limpias porque el dueño se dedica en la semana a vender agua ya que tiene una purificadora y entrega garrafones a domicilio. La cuestión aquí no es lavar por fuera los vehículos sino por dentro; es difícil porque me da miedo tener contacto directo con el interior del carro ya que el dueño y sus trabajadores van a muchos lugares a entregar agua y les vale ${ }^{2}$ la situación del coronavirus ya que ellos solo dicen que "son puras mamadas" ${ }^{\text {, }}$ en si no me da miedo enfermarme o contraer el virus, me preocupa contagiar a mi mamá" (Tzolkin Zapi, diario de campo, abril 12, 2020).

Se evidenciaban algunas tensiones entre quienes sostenían que era necesario respetar las normas de salubridad planteadas por el gobierno y aquellos que no creían en la existencia del virus o que no podían mantenerse en aislamiento porque laboraban en el sector informal de la economía. La policía intervino en varios mercados y ventas ambulantes intentando que las personas respetaran la distancia personal, hecho que derivó en enfrentamientos entre grupos policiales y vendedores (Dávila, 22 de abril de 2020). El siguiente relato permite acercamientos a esta tensión social:

Estábamos buscando en donde vendían recaudo ${ }^{4}$, para mi sorpresa la guardia nacional ${ }^{5}$ estaba vigilando y no permitía que los vendedores ubicaran sus puestos en la vía pública, pero las personas rentaron las entradas de las cocheras $^{6}$ de las casas vecinas para tener donde vender sus productos. Se defendían de los miembros de la guardia nacional con el argumento de que era propiedad privada y no los podían quitar. La gente que llegaba a comprar no tenía tapabocas, solo algunos pocos lo usaban. (Tzolkin Zapi, diario de campo, abril 14, 2020).

Llama la atención la reserva con la que varias personas tomaban las informaciones oficiales relacionadas con la pandemia y con las normas de seguridad. Los

\footnotetext{
${ }^{2}$ Expresión coloquial que hace referencia a que algo no les importa en lo absoluto.

${ }^{3}$ Esta expresión significa que son puras tonterías.

${ }^{4}$ La gente en el centro de México utiliza esta palabra para referirse a los productos que se consiguen en el mercado.

${ }^{5}$ La Guardia Nacional es una institución que cumple labores de policía nacional a nivel estatal en México.

${ }^{6}$ Esta palabra es un sinónimo de estacionamientos.
} 
estudiantes, durante su trabajo de campo, empezaron a darse cuenta de que algunos de sus familiares manifestaban vehementemente que los medios de comunicación estaban tergiversando la información porque obedecían a intereses económicos y políticos. Esta mezcla de desconfianza respecto a vínculos entre políticos, empresarios y medios de comunicación resultaba significativa y aludía a experiencias históricas que habían resultado negativas para los informantes. Posiblemente esta era una de las razones de la incredulidad respecto al virus que, según los medios de comunicación, se incrementaba de manera exponencial. Una de estas declaraciones planteaba el siguiente argumento:

Comíamos en la cocina los cuatro (papá, mamá y dos hermanos) y papá hablaba sobre el tema del Covid-19, decía que era una especie de conspiración y que por eso el periodista Javier Alatorre había dicho que no se hiciera caso al secretario de salud de México, según él porque Alatorre recibió esa orden de su jefe Ricardo Salinas Pliego. (Uziel Delgado, diario de campo, abril 18, 2020).

Para poder contextualizar esta aseveración es necesario precisar que el 23 de marzo Hugo López-Gatell, Subsecretario de Prevención y Promoción de la Salud de México, recomendó acatar las precauciones contempladas en la "Jornada Nacional de Sana Distancia", dentro de las que se encuentra el uso de tapabocas, quedarse en casa y mantener distancia entre las personas. Dos días después, el reconocido empresario Ricardo Salinas Pliego, propietario del grupo Azteca y de TV Azteca, mostró su preocupación por la paralización de las actividades cotidianas, señalando que el virus no es tan letal como lo decía el gobierno (La Política Online, 25 de marzo de 2020). Pocos días más tarde, Javier Alatorre, conductor del noticiero de TV Azteca, invitó a la población a no seguir las recomendaciones dadas por el Subsecretario de Prevención y Promoción de la Salud.

Esta declaración causó un gran debate nacional en torno a la necesidad o no de respetar las indicaciones gubernamentales relacionadas con el COVID-19. Evidentemente, se presenciaba una pugna entre un sector empresarial que privilegiaba la ganancia económica y una política que buscaba que el sistema de salud no colapsara por un posible aumento de contagios. Además, fue una oportunidad para exacerbar la duda respecto a posibles intereses del gobierno al proponer detener las actividades cotidianas, así como la desconfianza de algunas personas y grupos 
sociales frente a la histórica relación que los grandes empresarios han tenido con los medios de comunicación en México (Fernández Poncela, 2012).

\section{Reflexiones finales}

En México la desconfianza frente a las informaciones relacionadas con el COVID-19 tiene muchas aristas que no se pueden simplificar. Una de ellas es la percepción de que la mayoría de las noticias emitidas por los medios de comunicación oficial están relacionadas con estratagemas políticas para beneficiar a ciertos grupos de poder económico. Esta percepción se basa en experiencias reales que históricamente los mexicanos han vivido. Otra arista desde donde se puede analizar esta desconfianza está vinculada a las teorías de la conspiración, que se promueven por redes sociales, y que algunas personas utilizan como medio de información alternativo a los medios de comunicación oficiales.

Las estrategias simbólicas del gobierno de México han dificultado saber qué es cierto y qué no lo es en este contexto viral. El presidente de México ha sido reticente a utilizar cubrebocas aun cuando su mismo gobierno incluye este aditamento dentro de las normas de seguridad frente al COVID-19. El 15 de marzo del 2020 se desató un debate nacional porque, en pleno inicio de la pandemia, él, sin cubrebocas, alzó y besó a una niña durante una de sus giras nacionales (Aristegui noticias, 15 de marzo de 2020). El primer día que AMLO utilizó tapabocas fue el 7 de abril durante un viaje a Washington, Estados Unidos. Sin embargo, en eventos oficiales nacionales él insistía en no usar cubrebocas pese a que funcionarios de la Organización Mundial de la Salud (OMS) le recomendaban utilizarlo (Expansión, 2 de diciembre de 2020)

Esa desconfianza se prolonga hasta el día de hoy, un año después del inicio de la pandemia, y se evidencia en que aproximadamente el $20 \%$ de mexicanos no quiere ser vacunado por causas tan variadas como la creencia en los argumentos asociados a teorías conspirativas, la sospecha de que las vacunas generan traumatismos severos e incluso la muerte de quienes las reciben, y la firme creencia de que el virus no existe (El Universal, 1 de mayo de 2021).

La desconfianza frente a las informaciones acerca del COVID-19 se puede evidenciar en Latinoamérica y en otros lugares del mundo. Sin embargo, en un contexto con el $57 \%$ de informalidad laboral, con la mitad de la población con ingresos por debajo 
de la línea de bienestar y con altos niveles de corrupción, la desconfianza es un componente central en la vida social mexicana. También es cierto que la gente está buscando alternativas para salir a buscar su sustento diario, aunque esto implique desconocer las ambiguas indicaciones oficiales de salubridad, diseñar alternativas colectivas para evadir a la policía o arriesgarse a enfermar. En este escenario de incertidumbre y desinformación cualquiera puede estar diciendo la verdad y cualquiera puede contagiar.

\section{Bibliografía}

Aristegui noticias (15 de marzo de 2020). En tiempos de coronavirus, AMLO besa y abraza a la gente en su gira por Guerrero. Recuperado de: https://aristeguinoticias.com/1503/mexico/en-tiempos-de-coronavirus-amlobesa-y-abraza-a-la-gente-en-su-gira-por-guerrero/

Chance, J. K. y Taylor, W. B. (1985). Cofradías and Cargos: An Historical Perspective on the Mesoamerican Civil-Religious Hierarchy. American Ethnologist, 12(1), 126. DOI: 10.1525/ae.1985.12.1.02a00010

Dávila, I. (22 de abril de 2020). Comerciantes se enfrentan con policías durante operativo en Toluca. La Jornada. Recuperado de: https://www.jornada.com.mx/ultimas/estados/2020/04/22/comerciantes-seenfrentan-con-policias-durante-operativo-en-toluca-2175.html.

El Universal (1 de mayo de 2021). Santa María del Mar desconfió de vacuna. Recuperado de: https://www.eluniversal.com.mx/estados/santa-maria-delmar-desconfio-de-vacuna?fbclid=IwAROpGASt0g5jtohlBpadOmH4mrx9wKHUZM8CEjaEVaB5X T3UKFDdr2DZM

Expansión (2 de diciembre de 2020). AMLO insiste en no usar cubrebocas pese a 'regaño' de la OMS y aumento del COVID. Recuperado de: https://politica.expansion.mx/presidencia/2020/12/02/amlo-insiste-en-nousar-cubrebocas-pese-a-regano-de-la-oms-y-aumento-del-covid.

Fernández Poncela, A. M. (2012). Psicología de masas, identidad social, epidemias y rumores: la influenza en México. Sociológica, 27(76), 189-230. 
Gómez Carmona, G., Villar Calvo, A. y Inzulza Contardo, J. (2016). La reconfiguración urbana de ciudades intermedias mexicanas en el contexto latinoamericano. El caso de Metepec, México. Revista AUS, 19(11) 66-72. DOI: $10.4206 /$ aus.2016.n19-11

Jiménez Sánchez, P.L., Calderón Maya, J.R. (2016). Fragmentación y desarrollo habitacional en la Zona Metropolitana de Toluca. En Alvarado Rosas, C., Gómez Maturano, R, Hidalgo Dattwayler, R.(eds.), Expresión territorial de la fragmentación y segregación (53-72). México: Universidad Autónoma del Estado de Morelos.

La Política Online (25 de marzo de 2020). Alarmado por la recesión, Salinas Pliego pide que la gente vuelva a la calle: "Es un virus de baja letalidad. Recuperado de: $\quad$ https://www.lapoliticaonline.com.mx/nota/129234-alarmado-por-larecesion-salinas-pliego-pide-que-la-gente-vuelva-a-la-calle-es-un-virus-debaja-letalidad/

Magazine, R. (2015). El pueblo es como una rueda. Hacia un replanteamiento de los cargos, la familia y la etnicidad en el altiplano de México. Ciudad de México: Universidad Iberoamericana.

Mulhare, E. (2000). Mesoamerican Social Organization and Community after 1960. En Monaghan, J. (ed.), Supplement to the Handbook of Middle American Indians (9-23). Austin, Texas, Estados Unidos: University of Texas Press.

Ramírez López, B.P. (2019). El binomio formalidad/informalidad en el mercado de trabajo mexicano. Equidad y Desarrollo, 33, 89-103.

Robichaux, D. (2002). El sistema familiar mesoamericano y sus consecuencias demográficas: un régimen demográfico en el México indígena. Papeles de población, 8(32), 59-94.

Rodríguez Medina, L., Pandal de la Peza, A. y Shrum, W. (2019). Sobre la desconfianza en la ciencia y la política: el brote de zika en México, 2016-2018. Sociológica, 34(96), 205-238.

Strauss, A. y Corbin, J. (2002). Bases de la investigación cualitativa. Técnicas y procedimientos para desarrollar la Teoría Fundamentada. Medellín: Universidad de Antioquia. 